\title{
Photoluminescence topography of fluorescent SiC and its corresponding source crystals
}

\author{
Wilhelm, M.; Kaiser, M.; Jokubavicus, V.; Syväjärvi, M.; Ou, Yiyu; Ou, Haiyan; Wellmann, P.
}

Publication date:

2012

Link back to DTU Orbit

Citation (APA):

Wilhelm, M., Kaiser, M., Jokubavicus, V., Syväjärvi, M., Ou, Y., Ou, H., \& Wellmann, P. (2012).

Photoluminescence topography of fluorescent SiC and its corresponding source crystals. Abstract from

European Conference on Silicon Carbide and Related Materials (ECSCRM 2012), Saint-Petersburg, Russian Federation.

\section{General rights}

Copyright and moral rights for the publications made accessible in the public portal are retained by the authors and/or other copyright owners and it is a condition of accessing publications that users recognise and abide by the legal requirements associated with these rights.

- Users may download and print one copy of any publication from the public portal for the purpose of private study or research.

- You may not further distribute the material or use it for any profit-making activity or commercial gain

- You may freely distribute the URL identifying the publication in the public portal 


\title{
Photoluminescence topography of fluorescent $\mathrm{SiC}$ and its corresponding source crystals
}

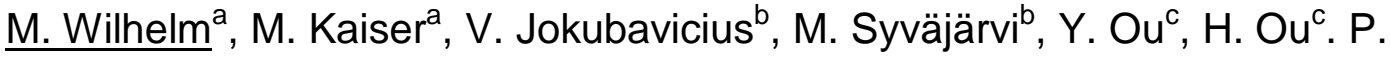 \\ Wellmann ${ }^{\mathrm{a}}$
}

Email: martin.wilhelm@ww.uni-erlangen.de

\author{
${ }^{a}$ Materials Department 6, University of Erlangen, Germany \\ ${ }^{\mathrm{b}}$ Department of Physics, Chemistry and Biology, Linköping University, Sweden \\ ${ }^{\mathrm{C}}$ Department of Photonics Engineering, Technical University of Denmark, DK-2800, \\ Lyngby, Denmark
}

High power and high efficiency electrical as well as opto-electrical devices need homogeneous $\mathrm{SiC}$ substrates of high quality for maximum performance. A promising method for substrate preparation is the Fast Sublimation Growth Process (FSGP), using poly-crystalline $\mathrm{SiC}$ (pc-SiC) source material. The source is important since it provides the dopants and is the growth rate determining step [1]. Due to the morphology and polytypism of the pc-Sic, the incorporation of the dopants in the source material varies in a wide range. In this work we investigated the effect of source structure on the homogeneity of the epitaxial layer and its fluorescent properties.

We measured the source crystals and the grown epitaxial layers by photoluminescence $(\mathrm{PL})$ topography at the energy of the Donor-Acceptor-Pair (DAP) recombination in $6 \mathrm{H}$, which is equivalent to $560 \mathrm{~nm}$. A $405 \mathrm{~nm}$ laser-diode was used for excitation. A PVT growth method [2] was used to prepare the source-crystals to fabricate two types of samples which were co-doped with boron at $100 \mathrm{ppm}$ (sample 1) and $50 \mathrm{ppm}$ (sample 2), respectively, at a constant N2 flow of $10 \mathrm{sccm}$. .

The topograms clearly show an inhomogeneity in luminescence for the pc-SiC source crystal which correlate with their grain structures (Fig. 1a+b and Fig. 2a+b). Sample 1 shows a direct correlation between polytype and luminescence intensity. Nearly all areas with high luminescence at $560 \mathrm{~nm}$ are 15R-SiC. Only the dark tinted regions show higher luminescence whereas the lightly tinted regions show much less intensity.

In Sample 2 it is not possible to correlate the luminance with the polytype, though the variation in luminance has to describe the variation in the dopant concentration. This correlation was already shown in Ref. [3]. The grain structure of the source crystal can be seen in Fig. 2a. Fig. 2b shows the corresponding PL-topogram. In comparison to sample $1,15 \mathrm{R}$-SiC does not result in the highest luminescence intensity which has to be due to the different doping concentrations. The luminescence is influenced by the dopant concentrations and the ratio between $\mathrm{N}$ and $B$ [4].

The picture of the grown epitaxial layer of sample 1 and its PL-topogram are shown in Fig. 1c and d, respectively. We observed a very homogeneous distribution of luminescence intensity which is equal to a homogeneous distribution of the dopants even though there are various polytype grains in the source. The higher 
luminescence intensity in the middle of the sample is due to a higher film-thickness. This film is almost completely $6 \mathrm{H}-\mathrm{SiC}$ but has a small inclusion of $3 \mathrm{C}$-SiC in the lower left corner visible as a dark spot in the luminescence topogram (Fig. 1d).

The other sample, shown in Fig. 2c and d, has much more 3C-SiC inclusions in the epitaxial layer due to the use of a low off-axis substrate [1]. There is no correlation between the $3 \mathrm{C}$ formation and the source crystal structure. Due to the high amount of $3 \mathrm{C}$ inclusions the homogeneity of the dopant distribution over the whole sample cannot be observed.

In summary: The granular polytype variation of the source material does not affect the homogeneity of the spatial luminance of the FSGP epitaxial layer. Defects in the epitaxial layer, in particular 3C-SiC inclusions, are attributed to general FSGP growth parameter variations rather than to the morphology of the poly-SiC source material.
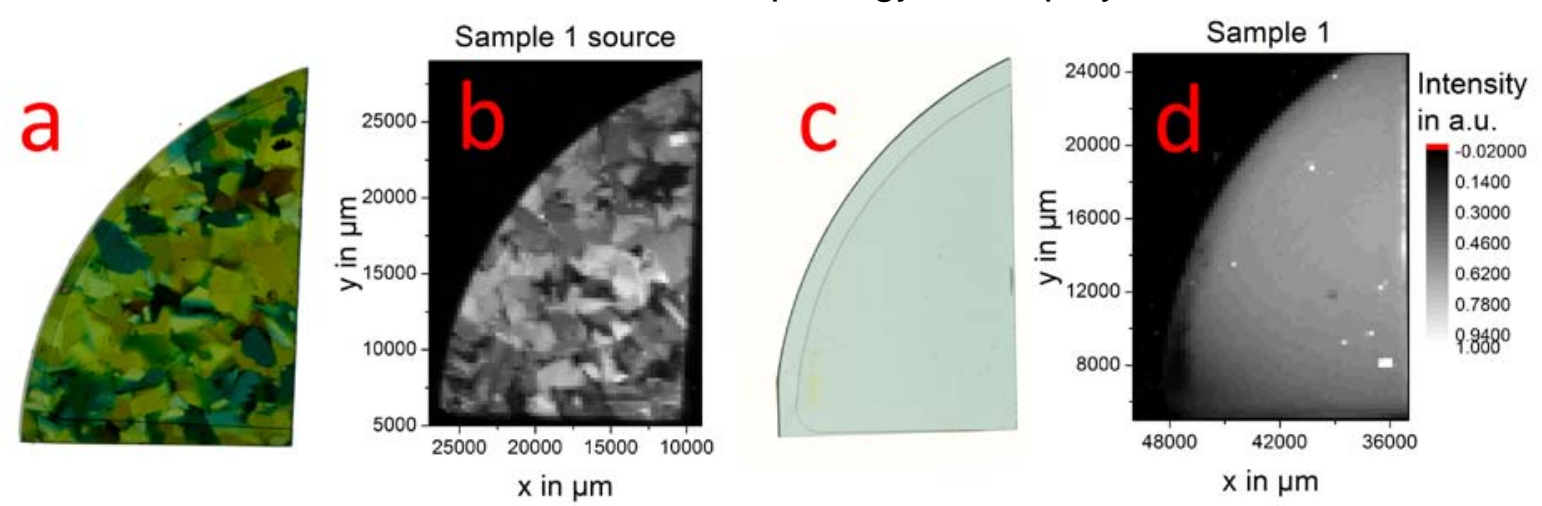

Fig. 1 a) Source used for sample 1 and its corresponding PL-topogram at $250 \mu \mathrm{m}$ resolution (b), c) Epitaxial layer of Sample 1 and its corresponding PL-topogram at $250 \mu \mathrm{m}$ resolution (d), c and d are mirrored for easier comparison

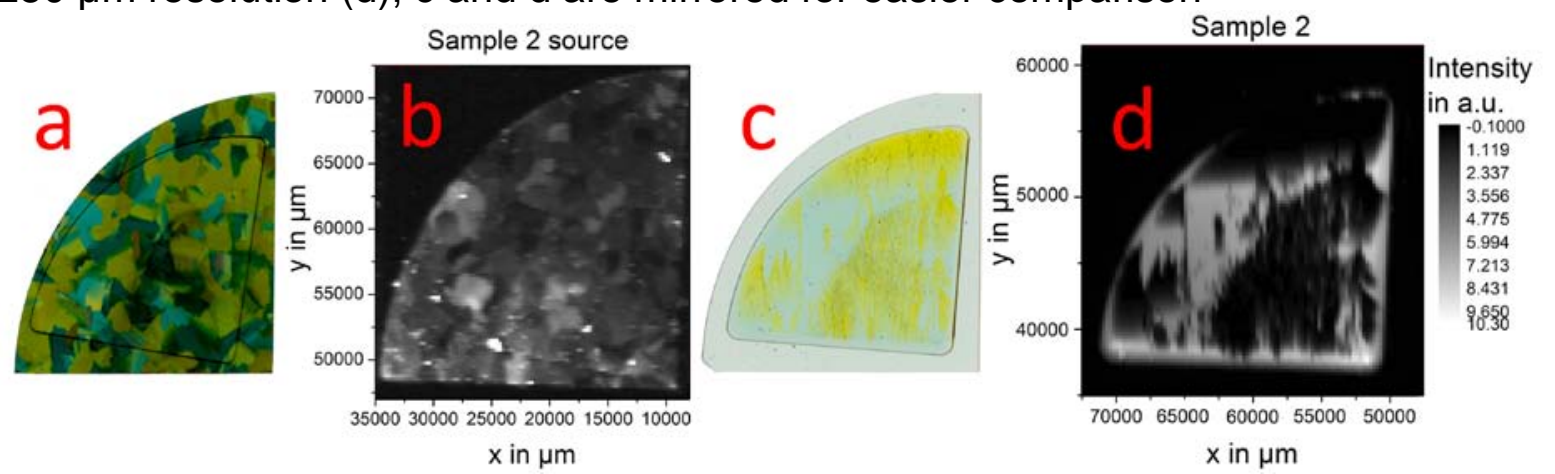

Fig. 2 a) Source used for sample 2 and its corresponding PL-topogram at $250 \mu \mathrm{m}$ resolution (b), c) Epitaxial layer of sample 2 and its corresponding PL-topogram at $250 \mu \mathrm{m}$ resolution (d), c and d are mirrored for easier comparison

\section{References}

[1] V. Jokubavicius, et al., Thin Solid Films (2011), doi:10.1016/j.tsf.2011.10.176

[2] P. Wellmann, P. Desperrier, R. Müller, T. Straubinger, A. Winnacker, F. Baillet, E. Blanquet, J. Marc Dedulle, M. Pons, J. Crystal Growth 275, e555 (2005)

[3] S. Murata, Y. Nakamura, T. Maeda, Y. Shibata, M. Ikuta, M. Sugiura, S. Nitta, M. Iwaya, S. Kamiyama, H. Amano, I. Akasaki, M. Yoshimoto, T. Furusho, H. Kinoshita, Material Science Forum 556-557, pp 335-338 (2007)

[4] Y. Ou, V. Jokubavicius, S. Kamiyama, C. Liu, R. W. Berg, M. Linnarsson, R. Yakimova, M. Syväjärvi, H. Ou, Optical Materials Express 1, 1439-1446 (2011) 